\title{
PENERAPAN ALGORITMA BEE COLONY UNTUK OPTIMASI RUTE WISATA
}

\author{
Adena Jaya Dilaga \\ Jurusan Teknik Informatika Fakultas Industri Kreatif dan Telematika Universitas Trilogi \\ Jln. TMP Kalibata No.1 - Daerah Khusus Ibukota Jakarta
}

adenadilaga@trilogi.ac.id

\begin{abstract}
Abstrak - Banyaknya tempat wisata di Pulau Belitung yang dapat dijangkau membuat kesulitan para traveler untuk mencari rute optimum, baik dari segi jarak, waktu, maupun biaya yang dikeluarkan untuk berpergian dari satu tempat wisata ke tempat wisata yang lain. Salah satu faktor yang mempengaruhi besarnya pengeluaran saat berwisata adalah biaya transportasi. Hal yang berhubungan erat dengan transportasi adalah jarak tempuh yang dilalui, terlalu banyak membuang waktu dalam perjalanan menuju tempat wisata dikarenakan salah dalam pemilihan rute yang ditempuh. Berdasarkan permasalahan yang ada maka dibutuhkan optimasi dalam pencarian rute optimum dari posisi awal menuju posisi tujuan dengan menggunakan Algoritma bee clony.
\end{abstract}

Kata kunci - Optimasi Rute, Rute Terpendek, Pulau Belitung, Algoritma Bee Clony.

\section{Pendahuluan}

Provinsi Kepulauan Bangka Belitung adalah provinsi ke-31 di Indonesia yang terdiri dari Kota Pangkalpinang, Kabupaten Bangka, Kabupaten Belitung, Kabupaten Bangka Barat, Kabupaten Bangka Tengah, Kabupaten Bangka Selatan dan Kabupaten Belitung Timur. Provinsi Kepulauan Bangka Belitung terdiri dari 3 pulau besar yaitu Pulau Bangka, Pulau Belitung, Pulau Lepar dan gugusan pulau-pulau kecil yang dipisahkan oleh laut dan pantai. Dengan Ibukota yang terletak di kota Pangkalpinang, Provinsi Kepulauan Bangka Belitung dikenal sebagai daerah penghasil timah terbesar di Indonesia dan memiliki pantai dengan panorama yang indah.

Pulau Belitung yang merupakan bagian dari Provinsi Kepulauan Bangka Belitung mempunyai potensi sumber daya alam yang potensial baik di laut maupun di darat. Di antaranya adalah potensi pariwisata bahari yang sangat menjanjikan untuk dikembangkan sebagai salah satu tempat destinasi wisata nasional. Selain itu, secara geografis Pulau Belitung memiliki letak yang sangat strategis dan mempunyai potensi sumber daya perikanan dan kelautan yang melimpah, baik dari segi diversivitas maupun kuantitas. Seiring dengan peningkatan jumlah kunjungan wisatawan dan juga meningkatan jumlah penduduk maka perlu adanya pengelolaan yang tepat agar jalannya kegiatan pariwisata di Pulau Belitung dapat berkelanjutan.
Masalah setiap traveler yang ingin melakukan kunjungan wisata biasanya membutuhkan informasi-informasi yang dapat mendukung suatu perjalanan. Beberapa diantaranya adalah informasi tentang tujuan tempat wisata dan rute perjalanan. Hal ini dapat dimanfaatkan oleh para penikmat traveler dalam memilih jalur yang akan ditempuh agar perjalanan menjadi lebih nyaman dan efisien dari segi jarak tempuh serta biaya. Dalam perjalanan, penentuan rute terpendek sangat dibutuhkan agar perjalanan menjadi lebih efisien dari segi jarak tempuh, waktu dan biaya yang dikeluarkan sampai tempat tujuan.

Melihat dari permasalahan yang ada maka diperlukan sebuah sistem yang dapat mengoptimasi rute terpendek sebuah perjalanan dari posisi awal sampai posisi tujuan. Algoritma bee colony optimization diterapkan pada masalah kunjungan ke objek wisata yang ada di Pulau Belitung. Pencarian rute terpendek diawali dengan mengetahui posisi asal dan tujuan wisata yang akan dikunjungi. Posisi asal dan tujuan wisata yang telah diketahui akan digunakan pada proses pembangunan tur perjalanan dan pencarian rute terpendek.

\section{Metodologi Penelitian}

\subsection{Swarm Intelligence}

Swarm Intelligence adalah salah satu teknik kecerdasan buatan yang berlandaskan kepada perilaku kolektif (collective 
behaviour) pada sistem yang terdesentralisasi dan dapat mengatur dirinya sendiri (self-organizing). Sistem yang memanfaatkan Swarm Intelligence biasanya merupakan sebuah populasi yang terdiri atas anggota berupa agen-agen yang sederhana, yang berinteraksi secara lokal dengan sesama anggota, dan juga berinteraksi dengan lingkungan.

\subsection{Algoritma Bee Colony Optimization}

Bee Colony Optimization adalah algoritma optimasi yang berdasarkan pada tingkah laku kumpulan lebah madu dalam sebuah koloni untuk menemukan sumber makanan. Kemungkinan solusi dilambangkan dengan posisi sumber makanan, sedangkan nilainya dilambangkan dengan jumlah nectar yang terdapat dalam sumber makanan tersebut.

Diasumsikan ada sebaran titik yang harus dilalui semuanya, semua titik terhubung secara langsung dengan titik-titik lainnya, dan semua jalurnya dapat dilalui 2 arah. Jarak antar titik pada semua titik akan diambil secara acak antara angka 1 sampai 10. Tentukan jalur yang harus diambil untuk mengelilingi semua titik dengan jarak terpendek.

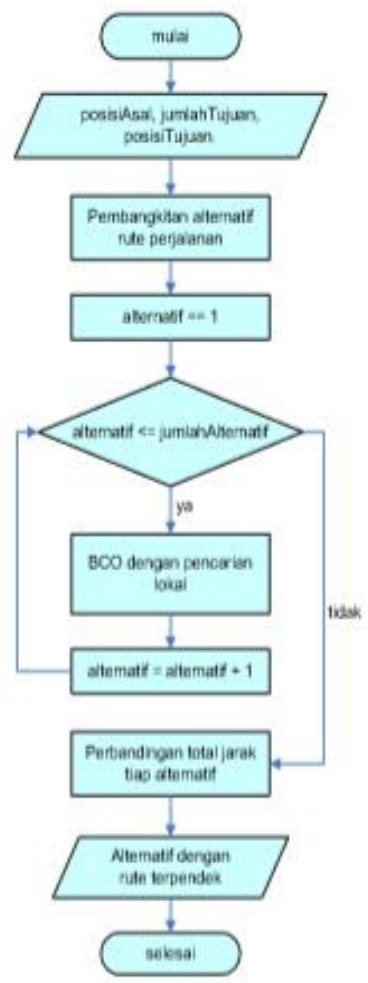

Gambar 1. Perancangan rute terpendek Algoritma Bee Colony

\section{HASIL DAN PEMBAHASAN}

Pengujian sistem dalam menemukan rute terpendek dilakukan pengujian dengan jumlah tujuan wisata yang berbeda, dan pengujian dengan jumlah lebah yang berbeda.

\subsection{Pengujian berdasarkan jumlah tujuan wisata}

Pengujian berdasarkan jumlah tujuan wisata dilakukan untuk melihat keberhasilan menemukan rute terpendek menuju tujuan wisata. Pengujian ini dibagi menjadi dua yaitu pengujian dengan 1 tujuan wisata dan $\mathrm{n}$ tujuan wisata.

Pengujian pertama dilakukan dengan 1 tujuan wisata. Pengujian pertama ini menggunakan parameter yang sama yaitu jumlah lebah $(\mathrm{NBee})=100, \alpha=1, \beta=2, \lambda=0.7$, dan $\mathrm{K}$ $=1$. Secara keseluruhan pengujian dilakukan sebanyak 50 kali. Jumlah tujuan wisata yang diuji sebanyak 10 tujuan wisata dimana setiap tujuan wisata dilakukan pengujian sebanyak 5 kali dengan posisi asal yang berbeda. Pengujian pertama terdapat 33 percobaan yang berhasil dan 17 yang tidak berhasil. Bila dipersentasekan ada $66 \%$ percobaan yang berhasil menemukan tujuan wisata dan $34 \%$ yang tidak berhasil menemukan tujuan wisata.

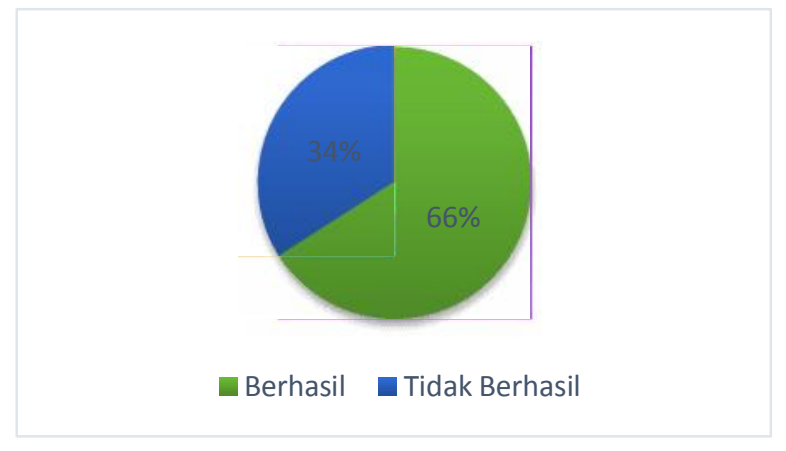

Gambar 2. Grafik perbandingan hasil pengujian dengan 1 tujuan wisata

Pengujian kedua adalah pengujian dengan $\mathrm{n}$ tujuan wisata. Pengujian dibagi menjadi dua yaitu dengan 2 tujuan wisata dan 3 tujuan wisata. Pengujian kedua ini menggunakan parameter yang sama yaitu jumlah lebah $($ NBee $)=100, \alpha=1$, $\beta=2, \lambda=0.7$, dan $K=1$. Pengujian dengan 2 tujuan wisata akan dilakukan sebanyak 25 kali. Jumlah kombinasi tujuan wisata yang diuji sebanyak 5 kombinasi dengan 5 posisi asal yang berbeda untuk setiap kombinasinya. Pengujian kedua ini diperoleh hasil yaitu dari 25 percobaan terdapat 18 percobaan yang berhasil dan 7 yang tidak berhasil. Bila dipersentasekan ada $72 \%$ percobaan yang berhasil menemukan tujuan wisata dan $28 \%$ yang tidak berhasil menemukan tujuan wisata. Tingkat keberhasilan pengujian dengan 2 tujuan wisata dapat dilihat dari grafik pada Gambar 3. 


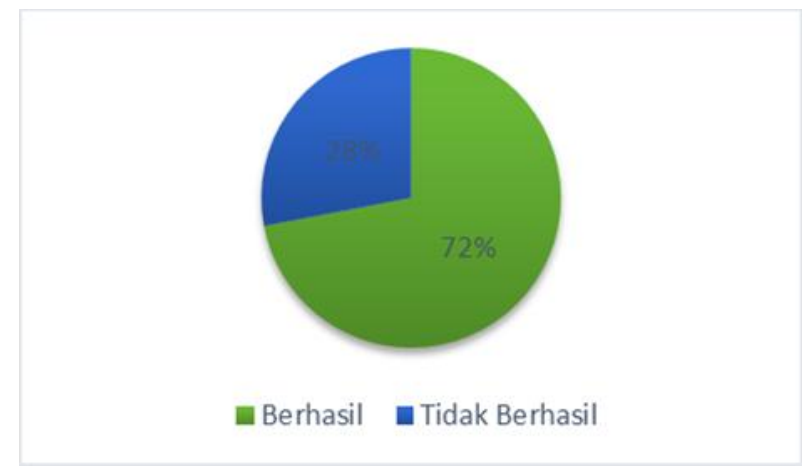

Gambar 3. Grafik perbandingan hasil pengujian dengan 2 tujuan wisata

Pengujian ketiga dilakukan dengan 3 tujuan wisata akan dilakukan sebanyak 25 kali. Jumlah kombinasi tujuan wisata yang diuji sebanyak 5 kombinasi dengan 5 posisi asal yang berbeda untuk setiap kombinasinya. Hasil pengujian ketiga terdapat 17 percobaan yang berhasil dan 8 yang tidak berhasil dari 25 percobaan yang dilakukan. Bila dipersentasekan ada $68 \%$ percobaan yang berhasil menemukan tujuan wisata dan $16 \%$ yang tidak berhasil menemukan tujuan wisata. Tingkat keberhasilan pengujian dengan 2 tujuan wisata dapat dilihat dari grafik pada Gambar 4.

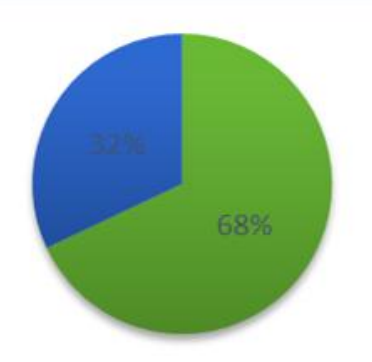

Berhasil a Tidak Berhasil

Gambar 4. Grafik perbandingan hasil pengujian dengan 3 tujuan wisata

Dari 3 pengujian diatas persentase keberhasilan menemukan tujuan wisata rata-rata $68 \%$. Pengujian pertama persentase keberhasilan sebesar $66 \%$, pengujian kedua dengan 2 tujuan taman sebesar $72 \%$ dan pengujian dengan 3 tujuan taman sebesar $68 \%$. Tingkat keberhasilan rata-rata menemukan tujuan taman dapat dilihat pada Gambar 5.

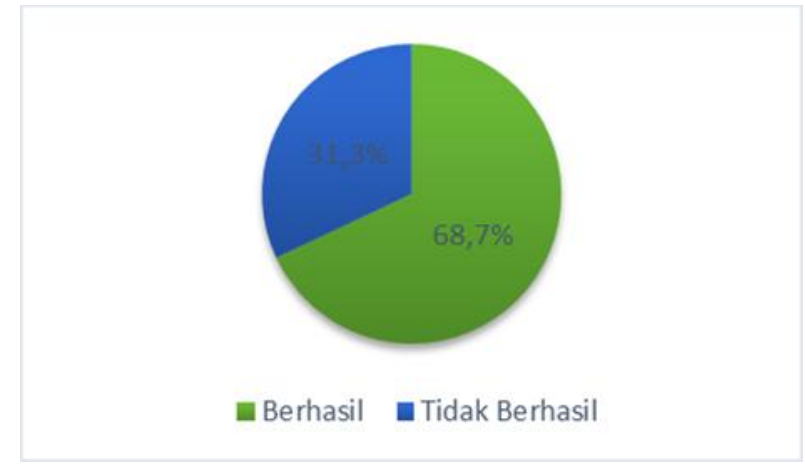

Gambar 5. Grafik tingkat keberhasilan rata-rata

\subsection{Pengujian berdasarkan jumlah Lebah}

Pengujian berdasarkan jumlah lebah dilakukan untuk melihat pengaruh jumlah lebah yang dilepas dalam menemukan rute terpendek menuju tujuan wisata.

Pengujian pertama menggunakan parameter yang sama yaitu $\alpha=1, \beta=2, \lambda=0.7$, dan $\mathrm{K}=1$. Pengujian pertama dilakukan dengan 1 ekor lebah. Pengujian berikutnya dengan 10, 50, 100, dan 300 ekor lebah. Secara keseluruhan pengujian dilakukan sebanyak 25 kali dengan 1 tujuan wisata sebanyak 10 kali dan 2 tujuan wisata sebanyak 10 kali dan 3 tujuan wisata 5 kali.

Tujuan wisata yang berjumlah 1 memiliki tingkat keberhasilan sebesar $80 \%$, hal ini ditandai dengan 8 percobaan yang berhasil dari 10 percobaan yang dilakukan.Tujuan wisata yang berjumlah 2 memiliki tingkat keberhasilan sebesar $80 \%$, hal ini ditandai dengan 8 percobaan yang berhasil dari 10 percobaan yang dilakukan. Tujuan wisata yang berjumlah 3 memiliki tingkat keberhasilan sebesar $40 \%$, hal ini ditandai dengan 2 percobaan yang berhasil dari 5 percobaan yang dilakukan. Rata-rata keberhasilan sebesar $66,7 \%$. Tingkat keberhasilan rata-rata menemukan tujuan taman dibawah pengaruh jumlah lebah dapat dilihat pada Gambar 6 .

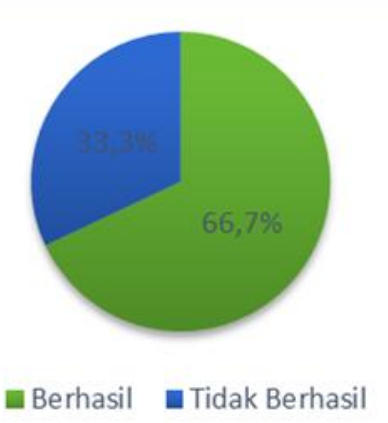

Gambar 6. Grafik tingkat keberhasilan rata-rata dibawah pengaruh jumlah lebah 


\section{KESIMPULAN}

Berdasarkan dari hasil pengujian penelitian Penerapan Algoritma Bee Colony Untuk Optimasi Rute Wisata Pulau Belitung, bahwa bagaimana sebuah algoritma menerapkan koloni lebah untuk di jadikan sebagai penelitian dan juga di lakukan percobaan untuk menentukan rute terpendek dari lokasi wisata satu menuju wisata lainnya.

\section{REFERENSI}

[1] Teguh, R., \& Nugraha, W. (2018). Penerapan Algoritma Bee Colony Untuk Optimasi Rute Tempat Wisata Kuliner di Bandung, 5(4), 349-352.

[2] Wong,L., Low, M.Y.H., and Chong, C.S., (2008). Bee Colony Optimization with Local Search for Traveling Salesman Problem, Proceeding of 6th IEEE International Conference on Industrial Informatics (INDIN 2008),Daejeon - Korea, 13 - 16 Juli 2008, 1019 - 1025.

[3] Kaur, A., Goyal, S., (2011), A Survey on the Applications of Bee Colony Optimization Techniques, International Journal on Computer Science and Engineering(IJCSE), India, 8 Agustus 2011, vol. 3, 3037 - 3046, ISSN : 0975 - 3397.

[4] Amri, F., Nababan, E. B. \& Syahputra, M. F., (2012). Artificial Bee Colony Algorithm untuk Menyelesaikan Travelling Salesman Problem. Jurnal Dunia Teknologi Informasi, 1(1), pp. 8-13.

[5] Danuri \& Prijodiprodjo, W., (2013). Penerapan Bee Colony Optimization Algorithm Jurnal Pengembangan Teknologi Informasi dan Ilmu Komputer 223 Fakultas Ilmu Komputer, Universitas Brawijaya untuk Penentuan Rute Terpendek (Studi Kasus : Objek Wisata Daerah Istimewa Yogyakarta). IJCCS, Volume 7, pp. $] 6576$.

[6] Yudhitiya, M. A. (2018). Penerapan Pencarian Rute Tercepat Aliran Air Menggunakan Algoritma Bee Colony Optimization, 5(4), 353-356.

[7] Hermawan, M. A., Hidayat, N., \& Setiawan, B. D. (2017). Sistem Optimasi Rute Tempat Wisata Kuliner Di Malang Menggunakan Algoritma Bee Colony, 1(3), 215-223. 